\title{
O sujeito e a visualidade: parábolas do olhar contemporâneo
}

\section{MARCELO SILVIO LOPES}

REGINA KRAUSS

Resumo

O presente artigo trata do percurso do olhar em seus diferentes tempos históricos, tomando como referencial a história das representações na arte. Para tanto, utiliza o conceito de subjetividade do observador na construção da visualidade apropriando-se das formulações de teóricos da imagem e da filosofia e discute de que modo esta construção cria um regime estético específico na contemporaneidade. 


\title{
The subject and visuality: parables of contemporary look
}

\author{
MARCELO SILVIO LOPES \\ REGINA KRAUSS
}

Abstract

This article talk about the trajectory of the eye at different historical times, taking as reference the history of representation in art. Therefore, using the concept of subjectivity of the observer in the construction of visuality appropriating formulations of the image and philosophy theorists and discusses how this construction creates a specific aesthetic in the contemporary time. 


\section{Introdução}

Centrado na problemática da construção da visualidade contemporânea, o texto discute a trajetória do olhar através dos diferentes momentos históricos da arte e de como diferentes tecnologias relacionadas à criação artística alteraram o modo como o sujeito percebe as representações e narrativas visuais.

Para compreender o que Lyotard definiu de sociedade "pós-moderna" e os atributos desta sociedade regida pelo excesso de informação visual em detrimento das experiências estéticas pensadas como sensações e sentimentos do corpo, este artigo refaz o percurso da história das artes plásticas, da fotografia, do cinema e dos aparatos de ver contemporâneos. A alternância do lugar do olho nos diferentes regimes de visualidade parte do conceito Medieval do corpo como instrumento da alma, passa pelo Renascimento, quando o homem assume a posição de centro das representações, pelo Barroco que coloca o homem dividido entre sua corporeidade e sua divindade, chega na transformação do sujeito pela possibilidade de virtualização do corpo através da fotografia, que viria engendrar todos os movimentos artísticos no início do século XX tipicamente modernos até chegar ao que se define aqui como 'regime de visualidade'.

\section{Um olhar inocente}

Descrever antropologicamente, ou seja, refletir acerca daquilo que é pertinente e característico de uma determinada sociedade em uma época determinada, é tarefa que se associa logo a um olhar histórico e historicizante. Histórico e prontamente, verbal e linear. Assim como Margaret Mead (1975) afirmou em 1973, a antropologia parece ainda uma disciplina de palavras, do Verbo e não de imagens. Temos 
aqui dois confrontos em relação ao nosso objeto: a perspectiva escolhida para se aproximar do sujeito contemporâneo foi a do olhar, das imagens que o direcionamento do olhar constrói e como ele as constrói, e também, dizê-lo através de imagens. O exemplo mesmo de Mead e Bateson, apesar de pioneiro, aponta a deficiência de se atrelar o uso de imagens ao relato de suas narrativas, dizendo o que está ou não presente na fotografia e implica afirmar que a observação direta pode ser transposta - sem prejuízo da credibilidade ou da objetividade - para a escrita. Essa ideia positivista da imagem invalida a presença e a contribuição da subjetividade e se contrapõe de imediato à máxima de Richard Wöllheim (2002, p. 16): "não existe um olhar inocente".

Também para Gombrich (1982, p.30), nossos julgamentos estão baseados em impressões visuais e sensações que se interpenetram de tal maneira que se torna difícil separar o que se percebe do que se infere, o que ele viria a denominar beholder's share, ou seja, o papel do espectador. Na obra 'A Imagem', Aumont retoma este pensamento para fundamentar sua análise sobre a imagem tratando da participação do espectador; quando diz que foi Gombrich, em sua célebre obra 'Arte e Ilusão' quem propôs a expressão 'papel do espectador', para assim designar o conjunto dos atos perceptivos e psíquicos pelos quais, ao perceber e compreender a imagem, o espectador faz com que ela exista.

(...) Gombrich adota, sobre a percepção visual, uma posição do tipo construtivista. Para ele, a percepção visual é um processo quase experimental, que implica um sistema de expectativas, com base nas quais são emitidas hipóteses, as quais são em seguida verificadas ou anuladas. Esse sistemas de perspectivas é amplamente informado por nosso conhecimento prévio do mundo e das imagens: em nossa apreensão das imagens, antecipamo-nos, abandonando as idéias feitas sobre nossa percepção. (AUMONT, 2004, p.86).

Na mesma linha, Couchot (2003, p. 4) cita o exemplo das obras impressionistas, nas quais a participação do observador é solicitada como condição imprescindível para a existência do trabalho, quando é a retina de quem vê a responsável pela síntese ótica das pinceladas estilhaçadas, para revelar pelo seu distanciamento ou aproximação, enfim, a obra. Este primeiro olhar revelador poderá então ser recriado infinitas vezes depois, pela lembrança de cores e luzes. 
Assim, o que Aumont (1994, p.105) chama de imagem mental é constituída por todos nossos mecanismos perceptivos e também por todos os vetores culturais que vão determinar padrões de percepção para determinadas sociedades em períodos distintos. Para o autor, pode-se encontrar no campo da imagem três conceitos presentes no ato de olhar: representação, ilusão e realismo. Se a representação permite ao leitor aproximar-se "por delegação" de uma realidade ausente, a ilusão é um fenômeno perceptivo provocado pela interpretação psicológica e cultural da representação e, por último, o realismo é visto como uma construção social de regras determinadas, é o que ele chama de uma forma consensual de "[...] um conjunto de regras sociais, com vistas a gerir a relação entre a representação e o real de modo satisfatório para a sociedade que formula essas regras".

Aproximar-se da realidade por encargo é um resquício rançoso da crença positivista de que a imagem está para a realidade como o ícone está para seu referente, por analogia direta, fé que se propagou com as descobertas científicas e tecnológicas sobre o processo físico da visão e a descoberta da fotografia e do cinema. Contra esta verdade imagética realista, pura, neutra e diretamente ligada ao espectador, se interpõe a ideia de "olho variável" de Aumont (2007, p. 53) que apresenta um modesto passageiro de trem ou o deslumbrado homem que freqüentava os Panoramas, como provas de que o olhar se direciona para aquilo que lhe chama a atenção e muda de interesse conforme o "enquadramento" que lhe põe a frente. Assim, o cinema ofereceu ao sujeito moderno não apenas a possibilidade de ver imagens em movimento, mas de ver a si mesmo. O espectador do cinema não apenas vê e se vê, ele vai além, reflete sobre o que vê, faz relações, constrói conceitos, prevê, ou seja, o homem do cinema é, de acordo com Aumont, "visível e vidente" ${ }^{1}$.

O surgimento da estrada de ferro causou uma remodelação espaço-temporal, não apenas geográfica. Houve uma perda das raízes e uma busca por aceleração. Aumont relaciona o viajante do trem ao espectador do cinema:

[...] a estrada de ferro, ou antes, as máquinas móveis a ela associadas - o vagão, a locomotiva -, modelaram também o imaginário, e a câmera, em certos aspectos, não está longe da locomotiva [...] trem e cinema transportam o sujeito para a ficção, para o imaginário, para o sonho e também para outro espaço onde as inibições são, parcialmente, sanadas (AUMONT, 2007, p. 53). 
O sujeito do trem substitui o espectador da pintura. Ao contrário deste, o primeiro possui o olho móvel e o corpo imóvel e é dotado de ubiqüidade e onividência, ou seja, é onipresente, está em todas as partes e pode ver tudo. Assim como no cinema, os viajantes do trem apreciam um espetáculo enquadrado. O olho móvel do passageiro passeia pela paisagem limitada pela janela do trem da mesma forma que o olho do espectador move-se pela tela do cinema. Ambos os sujeitos são considerados "sujeitos de massa" porque são, simultaneamente, anônimos e coletivos. Ao realizar uma viagem de trem ou assistir a um filme, os homens estão na presença de outras pessoas, ou seja, a experiência é realizada coletivamente. Porém, ao mesmo tempo, a apreciação da paisagem (no trem) e da narrativa (no cinema) se dá na esfera individual, pois o viajante e o espectador são, também, submetidos a emoções. Sentado, passivo, o viajante aprende depressa a observar o espetáculo enquadrado como outrem escolheu apresentá-lo. Os relatos dos viajantes e dos espectadores do cinema são praticamente idênticos: sujeitos transportados para outra esfera da vida privada, uma ficcionalização do aqui e mais além, um sujeito passível de ser 'neurotizado' na concepção freudiana de neurose, enfim, um sujeito tipicamente moderno.

Os irmãos Lumière, homens-símbolo da modernidade, trabalharam basicamente dois problemas na transformação do olhar: o efeito de realidade e a questão do enquadramento. $\mathrm{Ou}$ seja, problemas relacionados diretamente a questão fundamental: a liberação do olhar no século XIX. O cinematógrafo não é, aliás, por si só, o apogeu dessa liberação: ele aparece, - a coincidência é enorme - dois anos depois da primeira Kodak, a máquina que se gabava de pôr, enfim, o instantâneo ao alcance dos amadores. Lumière vai além e desloca de saída, neste terreno, tanto a pintura quanto o instantâneo fotográfico.

Cabe lembrar também a crítica radical de Flusser (2002), que desmistifica e disseca toda ilusão acerca da suposta neutralidade da imagem. Para ele, as imagens técnicas são pensadas como resultado de um programa tecnológico embutido na funcionalidade material e criam juízos sobre a realidade a partir desses programas, internos também à sua própria logicidade. Como um conceito que se instala na produção imagética humana a partir de seu programa tecnológico, a imagem técnica produz significações diferenciadas das significações do discurso verbal e das outras formas de percepção da realidade, ou nas palavras de Flusser (2002, p. 19), as imagens técnicas "[...] imaginam textos que concebem imagens que imaginam o mundo". 


\section{Regimes de visualidade}

Quando se observa a História, constata-se que o homem édotado de uma espécie de "olhar histórico", que cada época possuía uma visão particular de mundo e, de acordo com essa visão, cada época criava suas representações espaciais. Regime de visualidade (ROCHA; PORTUGAL, 2008) compreende o aprendizado sensorial que permite transformar estímulos nervosos em imagens com forma, luz e sombra, sendo este aprendizado baseado na experiência empírica e em certas regras sociais que estruturam tais experiências. As imagens se imbricam com os significados e com a dinâmica dos afetos, de modo que a relação homem/imagem é determinada por uma infinidade de regras sociais denominadas regimes de visualidade, ou seja, as formas de representar o mundo visível mudam de acordo com os regimes de visualidade de cada época e de cada lugar.

Comparando-se períodos históricos dentro da história da arte pode-se exemplificar o regime de visualidade que simboliza a contemporaneidade. O "espaço medieval" (século XII a $\mathrm{XV}$ ) apresenta um espaço hierático e hierárquico, refletindo uma posição histórica onde tudo o que existia eram Deus, homem e diabo. Geralmente, no mesmo plano, são superpostos as imagens dos santos em tamanho grande, os anjos um pouco menores, e os homens, quando eram representados, menores ainda. No "espaço renascentista" (século XV e XVI) as obras têm um caráter racional devido aos grandes descobrimentos da época, principalmente aos descobrimentos relativos à astronomia, corresponde a uma visão de mundo que privilegiava o homem como centro do universo, um espaço objetivo, matemático, homogêneo e sistemático. O todo está contido de maneira centralizada no espaço da obra. Pode-se considerar que a perspectiva renascentista é uma gramática da visão constituída por técnicas euclidianas e formalizada por Alberti, onde o homem se colocava como o centro do universo. No "espaço barroco" (século XVII) acontece exatamente o contrário; a paixão toma o lugar da racionalidade, a irregularidade e a assimetria apoderam-se da simetria. Nesse espaço, a perspectiva descentraliza-se, tornando-se diagonal, existindo na maioria das vezes um "outro" observador virtual com relação ao observador real da obra barroca. É nesse instante histórico que o homem tem a noção de infinito e já não se sente como o centro do universo, não sente o chão em que pisa, e essa "vertigem" se reflete no trompe l'oeil. O observador sempre olhando para o alto, ou lateralmente, para uma obra 
que contém parte do mundo e não o todo. Para Gullar (1988, p. 218) "[...] a percepção do homem é histórica. $\mathrm{O}$ homem não viu sempre a realidade como vê agora. Através da história o homem aprendeu a ver, criou modos de ver, desapareceu e criou outros modos". Pode-se citar ainda Couchot (2003, p. 15), "As técnicas, lembremo-nos, não são somente modos de produção, são também modos de percepção, formas de representações elementares, fragmentárias e estilhaçadas do mundo, que não tomam a via dos símbolos".

Para compreender de que modo de elabora a visualidade do sujeito contemporâneo, podemos tomar de empréstimo a observação de Durand (1998, p.7), que afirma vivermos em uma civilização das imagens, que se caracteriza pelo paradoxo e pela contradição. Uma sociedade gestada pelo Ocidente onde, de um lado, há um constante desenvolvimento da reprodutibilidade técnica (principalmente de imagens) e, por outro, demonstra uma sistemática desconfiança em relação às imagens, quase iconoclasta.

\section{A parábola do desterritorializado}

Há uma grande polissemia nos autores que discutem o termo desterritorialização. Para alguns pesquisadores o termo se refere ao desmoronamento das fronteiras, caracterizando o território como político, para outros, a desterritorialização está relacionada à hibridização cultural, fato que impossibilita o reconhecimento de identidades claramente definidas. Neste segundo caso, o território é simbólico, ou seja, um espaço de referência para a construção de identidades. Para Santos (2004), o território passa a ser criado no próprio desenvolvimento da História, com a apropriação humana de um conjunto natural pré-existente. Além dos aspectos políticos, o geógrafo também destaca a importância dos aspectos sociais, econômicos e culturais imbricados em virtude do movimento da sociedade no decorrer dos diversos momentos históricos e do desenvolvimento das técnicas.

Em Haesbaert (2004, p.19), lê-se a indagação: "O mundo estaria se "desterritorializando? Sob o impacto dos processos de globalização que "comprimiram" o espaço e tempo, [...] o que restaria de nossos "territórios", de nossa "geografia"? Na filosofia pós-estruturalista de Deleuze e Guattari (1997) que se encontra o conceito mais elaborado sobre territorialização e desterritorialização, um dos principais debates da chamada pós-modernidade, onde os discursos incluem diferentes di- 
mensões cotidianas, tais como econômica, política e cultura. De maneira simplificada, pode-se considerar a desterritorialização como um movimento pelo qual se abandona o território através de uma linha de fuga, movimento este seguido pela reterritorialização. Ambos os movimentos, desterritorialização e reterritorialização, funcionando como ato, ação, ritmo, na construção incessante do território. Muitos autores associam a característica desterritorializada da sociedade contemporânea como condição sine qua non à pós-modernidade. Ao romper com uma época, (HAESBAERT, 2004) o pós-modernismo inaugura uma nova sensibilidade, uma nova experiência de mundo que se vincula aos novos paradigmas tecnológicos que desestruturam antigos alicerces da sociedade com relação ao espaço. $\mathrm{O}$ uso das novas tecnologias gera um descentramento do indivíduo em relação a comunidades delimitadas, onde os contatos são cada vez mais virtualizados, eliminando a proximidade física. Os espaços físicos continuariam como veículos de ações concretas e processos de simbolização, mas permeados por novas funções e novas expressividades.

Desta maneira, a exaltação do sensível (SANSOT, 1986), a velocidade e os perigos (COUCHOT, 2003), o sensualismo coletivo (MAFFESOLI, 1990), o realismo sensorial (DURAND, 1984) são expressões conceituais que tentam definir a configuração da experiência humana nas grandes metrópoles contemporâneas. Uma experiência que se altera e comove por imagens, objetos e pessoas que são transformadas em informações sensíveis através dos inúmeros arranjos que a vida social assume quando na paisagem contemporânea urbana: conjunto de formas, de cores, de sons, de luminosos neons que formam o campo da cultura que hoje se configura por expressões verbais e corporais, ambiências sonoras, atmosferas artísticas fragmentadas através das quais o sujeito cria e recria sua identidade e seu modo de olhar. Há uma relação entre produção cultural e os modos de subjetividade nas sociedades capitalistas contemporâneas (JAMESON, 2004), relação esta marcada pela fragmentação e falta de profundidade, de características dispersivas e esquizofrênicas, instável, descontínua e descentrada.

Esse é o verdadeiro momento da sociedade da imagem, na qual, segundo Paul Willis, os sujeitos humanos, já expostos ao bombardeio de até mil imagens por dia, vivem e consomem cultura de maneiras novas e diferentes. Se as obras de arte high tech tematizadas tecnologicamente ofereciam as estruturas de um tipo de reflexividade ou autoconsciência a 
respeito de nossa atual situação e de sua relação com a tecnologia da informação, é tentador sugerir que no momento pós-moderno a reflexividade como tal se submerge na pura superabundância de imagens como em um novo elemento no qual respiramos como se fosse natural. (JAMESON, 2004, p.135).

De como chegamos a esse modo de ver e apreender que, titubeantes, chamamos 'pós-moderno', é algo que pode ser exemplificado com a imagem de um adolescente em um shopping de qualquer grande metrópole - como São Paulo, vestindo uma camiseta da Nike, ouvindo a banda alemã de tecno minimalista Krafwerk nos fones enquanto observa um telão com imagens de uma catástrofe na Tailândia em tempo real, carregando na bolsa um amuleto indígena guardado do último mochilão pela América Latina. Em que tempo e em que espaço está este sujeito desterritorializado? (GUATTARI, 1993). Qual o zeitgeist desta paisagem?

O conceito de "pós-modernismo» é de definição tão esotérica como o é o de um Deus omnipresente. Trata-se de um termo criado para descrever fenômenos tão diversificados como os filmes da Guerra das Estrelas, a prática de amostragem digital na música rock, campanhas políticas com recurso aos meios televisivos e as criações de moda de Jean Paul Gautier e Issey Miyake, e parece constituir o reflexo da vida contemporânea. (HEARTNEY, 2002, p. o6).

Para a autora, a pós-modernidade acontece lá onde se dá o desmoronamento da identidade do sujeito, a autoridade cultural já não se sustenta pelos mesmos alicerces, se passa do processo artístico da produção para a reprodução, o que implica cópia, pasteurização, amálgama de estilos, escolas e conceitos, o uso proposital do fake e do kitsch. O que Heartney faz é sistematizar diferentes referenciais do pensamento artístico-filosófico que dominaram a discussão sobre o sujeito/identidade/contemporaneidade. Pode-se citar significativamente Lyotard, que definiu a condição pós-moderna como um estado de incredulidade em relação às metanarrativas (Lyotard, 1984), propondo com o aforismo que a base da experiência da pós-modernidade decorreria da perda das crenças em visões totalizantes da História, que prescreviam regras de conduta política e ética para toda a humanidade. As metanarrativas foram substituídas por narrativas menores e múltiplas que não buscam (nem obtém) significado, unidade, legitimação ou 
universalidade. Outro conceito citado pela autora é o de simulacro e simulação, que alardeado por Baudrillard, classifica a nossa época como hiper-real, onde a imagem passa por quatro fases, iniciando-se com aquela em que reflete uma realidade primeira, para então mascarar e perverter esta realidade, depois mascarar a ausência de uma realidade primeira e, por fim, a imagem não mantém qualquer relação com qualquer realidade: é o seu próprio simulacro. No pós-moderno há também a presença de uma antiestética, no sentido de resistência ao significado original do termo estética, como sensibilidade de sentidos e de corpo, aisthesis. Não é o estudo do belo na arte que caracteriza a estética e sim a veiculação desse estudo a uma experiência que não é adquirida através da razão, mas da emoção, da sensibilidade, uma experiência originada diretamente no corpo orgânico, daquilo que é sensível a ele.

A estética nasceu como um discurso sobre o corpo. Em sua formulação original, pelo filósofo alemão Alexander Baumgarten, o termo não se refere primeiramente à arte, mas, como o grego aisthesis, a toda a região da percepção e sensação humanas, em contraste com o domínio mais rarefeito do pensamento conceitual. A distinção que o termo "estética" perfaz inicialmente, em meados do século XVIII, não é aquela entre "arte" e "vida", mas entre o material e o imaterial: entre coisas e pensamentos, sensações e idéias; entre o que está ligado a nossa vida como seres criados opondo-se ao que leva uma espécie de existência sombria nos recessos da mente. (EAGLETON, 1993, p. 17).

Apresentando-se de modos diferentes na História, a estética pode ser denominada como uma manifestação do regime de visualidade de determinada época.

\section{A parábola do Ornitólogo}

O território como ato afeta os meios e os ritmos, que por sua vez voltam a se desterritorializar e a reterritorializar. (DELEUZE; GUATTARI, 1997a) Portanto, o território não se apresenta apenas como conjunto de objetos, mas principalmente como ação e movimento que se repete. Há território quando o ritmo se torna expressivo, como no canto territorial dos pássaros. $\mathrm{O}$ território, antes de oferecer um desempenho, é possuidor de qualidades expressivas, é "um resultado da arte". Estas qualidades expressivas estariam presentes também nos próprios 
animais, por exemplo, na cor dos pelos e penas, no canto de alguns pássaros, no cheiro.

O canto territorial é uma assinatura, o pássaro diz: "este espaço é meu". É meu para quê? Para que ele exerça as suas funções alimentares, amorosas, de caça... Ou seja, as funções de um corpo de pássaro são secundárias; pressupõem a produção de um território. E o que estou chamando de função é o corpo orgânico. Eu estou dizendo pra vocês que o corpo orgânico tem que ser produzido, ele tem que ser produzido - e o pássaro faz essa produção cantando: ele produz um território; delimita o território dele. É de uma beleza extraordinária! (ULPIANO, 2010).

Segundo Orreda (2008) o ornitólogo e músico francês Olivier Messiaen estudou os pássaros por várias décadas e classificou os cantos em quatro tipos: $\mathbf{O}$ canto de alarme canto do tipo orgânico, para proteção do corpo orgânico. Na proximidade do predador, o pássaro emite um grito ou canto que os outros pássaros entendem e se refugiam. $\mathbf{O}$ canto da primavera - Canto do tipo orgânico, para reprodução do corpo orgânico. Canto amoroso, do acasalamento. Os machos cantam desesperadamente para conquistar as fêmeas. O canto territorializante - Canto do tipo estético, ainda orgânico. Destina-se a marcar o território. São mais bonitos que os cantos do amor. Estabelecem torneios entre si e, se um pássaro entender que o canto do outro é superior, ele sai. Os pássaros são éticos. Aquele que cantar com mais beleza fica com o território e ali faz seu ninho. $\mathbf{O}$ canto do crepúsculo - Canto do tipo estético, de um corpo sem órgãos. Canto original do gênero chamado tordo. Se o canto de alarme vem de fora, o canto do crepúsculo vem de dentro. Num crepúsculo mais longo, quando as cores fortes e tons de violeta demoram a desaparecer, quanto mais intenso as cores, mais agudo é o canto do pássaro. Ele abandona seus interesses orgânicos e se volta para a imagem do crepúsculo, na construção de um "corpo sem órgãos" (DELEUZE; GUATTARI, 1997b). Os autores se apropriam desse conceito formulado originalmente por Artaud, que, segundo Moraes (2002, p. 70), considerava urgente a tarefa de encontrar o espaço corporal da liberdade, colocando o homem a nu.

Um CsO [corpo sem órgãos] é feito de tal maneira que ele só pode ser ocupado, povoado por intensidades. Somente as in- 
tensidades passam e circulam. Mas o $\mathrm{CsO}$ não é uma cena, um lugar, nem mesmo um suporte onde aconteceria algo. Nada a ver com um fantasma, nada a interpretar. O CsO faz passar intensidades, ele as produz e as distribui num spatium ele mesmo intensivo, não extenso. Ele não é espaço e nem está no espaço, é matéria que ocupará o espaço em tal ou qual grau - grau que corresponde às intensidades produzidas. Ele é a matéria intensa e não formada, não estratificada, a matriz intensiva, a intensidade $=\mathrm{O}$, mas nada há de negativo neste zero, não existem intensidades negativas nem contrárias. Matéria igual a energia. Produção do real como grandeza intensiva a partir do zero. (DELEUZE; GUATTARI, 1996, p. 12).

Para Ulpiano (2010) qualquer corpo vivo apresenta duas forças: a orgânica conservativa, pertencente ao corpo orgânico, e a força estética, pertencente ao corpo expressivo, ou corpo sem órgãos, ou aos fluxos intensivos. "[...] o mesmo pássaro teria em seu corpo duas forças: uma força de conservação e uma força selvagem, violenta, conquistadora - cujo único objetivo seria a criação, a invenção e a produção. É como se fosse uma auto-poiesis: um poder autocriativo que passaria naquele corpo".

\section{Conclusões}

O primeiro pressuposto relacionado ao olhar a ser esquecido deve ser, certamente, a recorrente ideia positivista de que entre observador e imagem há apenas um circuito óptico sináptico de apreensão sem intermediários onde o repertório não interfere. Não só o olho é variável, como afirmaria Aumont, como a própria evolução das tecnologias digitais revela estes esquemas cambiantes de produção e edição de imagens.

Percebe-se que os diferentes 'olhares históricos' transformaram também completamente a posição do corpo no contexto social, não apenas porque o olho é um órgão humano, mas porque ele desloca também os outros sentidos e altera as relações de tempo/espaço do sujeito moderno e pós-moderno.

Observa-se na linha histórica do tempo a virtualização dos sentidos humanos, principalmente a virtualização do olhar que se inicia na repentina inflação demográfica das cidades, passando pela invenção da máquina fotográfica, do cinema, do vídeo, e culmina no computador. Essa virtualização da cognição humana se reflete em suas expressões artísticas; na revolução duchampiana, no Impressionismo, no Cubismo, no Surrealismo, em todas as vanguardas artís- 
ticas, e na contemporaneidade se reflete nas artes sistêmicas, digitais e telemáticas.

Conclui-se que qualquer incursão na análise do sujeito contemporâneo e sua relação com o olhar passa necessariamente pela ideia de visualidade extrema e saturada, pós-moderna, na qual a proposição do corpo físico, do corpo orgânico, se retrai e se amputa em benefício do uso dos sentidos ligados apenas à distância, como ouvir e, principalmente, ver. Assim, o homem pós-moderno necessita reconquistar seu corpo sem órgãos num retorno à aisthesis, necessita recuperar seu corpo expressivo.

\section{Referências Bibliográficas:}

AUMONT, Jacques. A Imagem. Campinas: Papirus, 1994. AUMONT, Jacques. O olho interminável - cinema e pintura. São Paulo: Cosac \& Naify, 2007.

COUCHOT, Edmond. A tecnologia na arte: da fotografia à realidade virtual. Trad. Sandra Rey. Porto Alegre: Ed. UFRGS, 2003.

DELEUZE, Giles; GUATTARI, Félix. Mil platôs - capitalismo e esquizofrenia, vol. o3; Trad. Aurélio Guerra Neto ET Al. Rio de janeiro: Ed. 34, 1996.

Mil platôs - capitalismo e esquizofrenia, vol. 04; Trad. Suely Rolnik. São Paulo: Ed. 34, 1997 . . Mil platôs - capitalismo e esquizofrenia, vol. 05; Trad. Peter Pál Pelbart e Janice Caiafa. São Paulo: Ed. 34, 1997b.

DURAND, Gilbert. O imaginário. Rio de Janeiro: Difel, 1998.

EAGLETON, Terry. A ideologia da estética. Trad. Mauro Sá Rego Costa. Rio de Janeiro: Jorge Zahar, 1993.

FLUSSER, Vilém. Filosofia da caixa preta: ensaios para uma futura filosofia da fotografia. Trad. do autor. Rio de Janeiro: Relume Dumará, 2002.

GOMBRICH, Ernst. The image and the eye: further studies in the psychology of pictorial representation. London: Phaidon, 1982.

GULLAR, Ferreira. Barroco, olhar e vertigem. In: NOVAES, Adauto (et al.). $O$ olhar. São Paulo: Companhia das letras, 1988.

GUATTARI, Félix. Caosmose - um novo paradigma estético. Trad. Ana Lúcia de Oliveira e Lúcia Cláudia Leão. São Paulo: Ed. 34, 1993.

HAESBAERT, Rogério. O mito da desterritorialização: do "fim dos territórios" à multiterritorialidade. Rio de Janeiro: Ber- 
trand Brasil, 2004.

HEARTNEY, Eleanor. Pós-Modernismo. Trad. Ana Luiza Dantas Borges. São Paulo: Cosac Naify, 2002.

JAMESON, Fredric. Espaço e imagem: teorias do pós-moderno e outros ensaios. Trad. Ana Lúcia Almeida Gazzola. Rio de janeiro: Ed. UFRJ, 2004.

LYOTARD, Jean-François. A condição pós-moderna. São Paulo: José Olympio, 2002.

MAFFESOLI, Michel. Aux creux des apparences. Paris: Plon, 1990.

MEAD, Margaret. Visual Anthropology in a discipline of words. In Principles of Visual Anthropology. Paris: The Hague, 1995 p. 3-12.

MORAES, Eliane Robert. O corpo impossível. São Paulo: Iluminuras, 2002.

ORREDA, José Maria. O canto dos pássaros. In: Revistas do Centenário. 02/05/2008. Disponível em http://www.iratiorredahistoria.com.br/web/index.php?option=com_con tent\&task=view\&id=12\&Itemid=9 . Acesso em o8/12/2009.

ROCHA, Rose de Melo; PORTUGAL, Daniel B. Trata-se de uma imágica? Hibridação, visibilidade e (ir)realidade da imagem. In: ARAÚJO, Denize. Correa.; BARBOSA, Marialva Carlos (Orgs.). Imagíbrida: comunicação, imagem e hibridação. Porto Alegre: Plus, 20o8. Disponível em: <http:// editoraplus.org/wpcontent;uploads;imagibrida.pdf $>$. Acesso em: 12 de Maio de 2010.

SANSOT, Pierre Les formes sensíbels de la vie sociale. Paris: PUF, 1986.

SANTOS, Milton. A natureza do Espaço - técnica e tempo, razão e emoção. São Paulo: Edusp, 2004.

ULPIANO, Cláudio. A potência não orgânica da vida. Disponível em: http://claudioulpiano.org.br.s87743.gridserver. com/?p=1531\#more-1531. Acesso em 03/o8/2010.

WÖLLHEIM, Richard. A pintura como arte. São Paulo: Cosac \& Naify, 2002.

1. Tal conceito é tomado emprestado do pensamento de Merleau-Ponty, para quem o corpo humano se caracteriza por ser, a um só tempo, visível e vidente, mergulhado em um mundo que não pára de se fazer ver.

Recebido em: 16/o6/10

Aceito em: 27/10/10 


\section{MARCELO SILVIO LOPES}

marcelo@marcelominka.com

O autor possui Licenciatura em Artes Plásticas pela Universidade Estadual de Londrina, é especialista em Comunicação Visual: Mídias Interativas pela UNOPAR. Mestrando em Comunicação também pela UEL.

\section{REGINA KRAUSS}

reginakraussuel@gmail.com

Graduada em Comunicação Social - Habilitação Jornalismo pela

Universidade Estadual de Londrina. Mestranda em Comunicação da mesma instituição. Bolsista da Capes. 